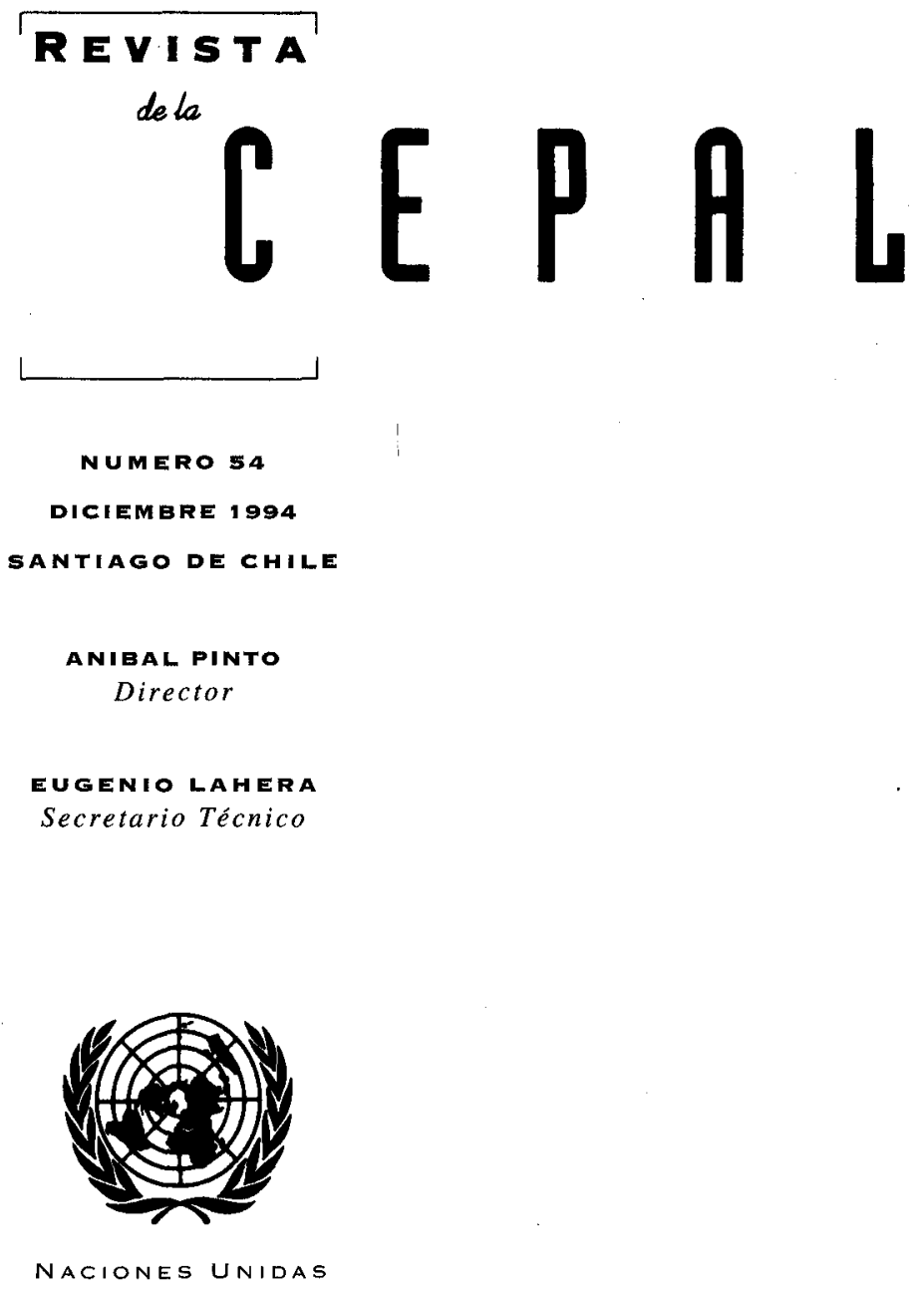


Mercados de salud: morfología, comportamiento y regulación

Jorge Katz y Ernesto Miranda

¿Liberalización o desarrollo financiero?

Günther Held

Ajuste fiscal y gasto social

Rossella Cominetti

Logros y obstáculos en la educación formal de las mujeres

Diane Alméras

¿Qué se entiende por flexibilidad del mercado de trabajo?

Ricardo A. Lagos

Modernización de la supervisión bancaria

Christian Larraín

Costos y beneficios de la integración centroamericana

Luis Cáceres

Algunas enseñanzas de las privatizaciones en Argentina

Daniel Azpiazu y Adolfo Vispo

Ventajas comparativas extraordinarias y crecimiento a largo plazo:

el caso de Ecuador

André A. Hofman y Rudolf Buitelaar

Industria cultural y nuevos códigos de modernidad

Martín Hopenhayn

Orientaciones para los colaboradores de la Revista de la CEPAL

Publicaciones recientes de la CEPAL 


\section{Algunas enseñanzas de las privatizaciones en Argentina}

\section{Daniel Azpiazu Adolfo Vispo}

Miembro de la Carrera de Investigador Científico del CONICET Investigador Principal de la FLACSO, Programa Argentina.

Consultor Externo de la Oficina de la CEPAL en Buenos Aires e Investigador Visitante de la FLACSO, Programa Argentina.
La desestatización de las economías latinoamericanas se ha ido constituyendo en uno de los temas centrales en el debate en torno al proceso de reestructuración económico-social de la región. Por la magnitud y celeridad de sus realizaciones, el programa desarrollado en la Argentina a principios de los años noventa emerge como un paradigma que invita a la reflexión, y deja una amplia gama de enseñanzas para aquellos países que procuren maximizar los beneficios sociales que pudieran derivarse de la privatización de empresas públicas. En esa perspectiva, el presente artículo resalta algunas de las principales repercusiones macroeconómicas de tales privatizaciones (fiscales, en el sector externo, en la estructura de precios relativos, en la inversión), así como sus efectos sobre la conformación de los mercados y las estrategias de los principales conglomerados empresariales del país, las formas que ha asumido la regulación pública de las áreas privatizadas, y las limitaciones e insuficiencias observadas. El análisis concluye que el énfasis cortoplacista probablemente conspiró contra la consecución de buena parte de los objetivos propuestos, y se apartó de los criterios emanados de la incipiente experiencia internacional en la materia. La desatención oficial a ciertos temas fundamentales (transparencia de los procesos, saneamiento previo de las empresas por privatizar, maximización del precio de transferencia, ejercicio del poder regulatorio, competitividad de los mercados y de la economía en su conjunto, consolidación de reservas de mercados oligopólicos, etc.) conllevó un aporte sólo marginal — si no negativo- a la equidad social en el país. 


\section{I}

\section{Introducción}

En consonancia con diversas experiencias internacionales contemporáneas, en los años ochenta se incorporó un nuevo tema a la agenda de la sociedad argentina: la "desestatización" de las empresas públicas.

Desde fines de los años setenta, la economía internacional asiste a un creciente cuestionamiento de muchas de las formas que adopta la regulación estatal $y$, en especial, de la propiedad pública de empresas prestadoras de servicios y, más aún, de las productoras de bienes.

La Argentina no ha permanecido ajena a ese fenómeno. Ya en la gestión gubernamental democrática de 1983-1989 se manifestaron los primeros ensayos ${ }^{1}$ de privatizar algunas de las principales empresas públicas. Tales proyectos fueron bloqueados por los legisladores del principal partido de oposición, que cuestionaron -en su esencia y en sus formas- las privatizaciones propuestas. $^{2}$

No obstante, a poco de asumir la actual administración a mediados de 1989, ese mismo partido logró la aprobación legislativa — casi sin oposición- de un ambicioso programa de privatizaciones, mucho más difundido y acelerado que el que había cuestionado poco tiempo antes. A partir de allí, con la promulgación de la ley 23696 de Reforma del Estado (agosto de 1989), el papel del sector público en la Argentina entró en una nueva fase, con la emergencia de nuevos mercados para la actividad privada y de áreas privilegiadas con cuasirentas extraordinarias y reservas de mercado. ${ }^{3}$ A partir de dicha ley quedaron sujetas a privatización, bajo diversas modalidades, prácticamente todas las empresas dedicadas a la producción de

$\square$ Estudio realizado como aporte al Proyecto "Transición de sistemas económicos", con la cooperación del Dr. Klaus Esser, del Instituto Alemán de Desarrollo. Este proyecto se desarrolla en la FLACSO, Programa Argentina, con el auspicio de la Stiftung Wolkswagenwerk.

1 Se trata de los intentos truncos por privatizar las empresas estatales de aeronavegación (Aerolíneas Argentinas) y de telecomunicaciones (ENTEL).

2 Las intenciones gubernamentales involucraban a diversas empresas públicas. Sin embargo, las privatizaciones concluidas en el período se vieron circunscritas, en lo esencial, a las tenencias accionarias en dos petroquímicas y a la planta de tubos con costura de la ex Siam.

3 Así había sucedido, en forma discontinua, durante los años ochenta con la estatización de la deuda externa privada, la promoción industrial, las compras de bienes y servicios del sector público, etc. bienes y servicios de propiedad - total o parcialdel Estado.

En general, los primeros pasos del difundido programa de privatizaciones sufrieron inconvenientes de diversa índole 4 que, en muchos casos, alteraron las condiciones previstas y los ambiciosos cronogramas originales. No obstante, si en algo destaca el ejemplo argentino respecto de otras experiencias internacionales relativamente contempóraneas, es en la celeridad y amplitud de las realizaciones. En efecto, entre 1990 y 1991 se privatizaron las empresas de telecomunicaciones, de aeronavegación, tenencias accionarias en la industria petroquímica, áreas centrales y secundarias de la explotación petrolífera, más de un tercio de la red nacional de carreteras, más de $5000 \mathrm{~km}$ de ramales ferroviarios, etc. Por su parte, en 1992 y 1993 el proceso de privatizaciones llegó a nuevos e importantes sectores (en especial, los energéticos), al tiempo que se profundizó en otros. Basta señalar que se privatizaron el transporte y la distribución del gas natural, la energía eléctrica (generación, transporte y distribución), las Obras Sanitarias de la Nación, diversos elevadores portuarios, las dos empresas siderúrgicas integradas (SOMISA y Altos Hornos Zapla); que se continuaron y profundizaron los procesos privatizadores en la explotación petrolífera de áreas centrales y secundarias - se le agregaron las refinerías, los oleoductos, la flota y otros activos de Y.P.F.-, y se privatizó parcialmente la propia Y.P.F., ramales ferroviarios y subterráneos, la red caminera y los accesos metropolitanos, tenencias accionarias en empresas industriales petroquímicas, empresas del área de Defensa y otros entes (el Hipódromo, el Mercado de Hacienda de Liniers, más de 800 inmuebles, etc.).

Este acelerado y vasto programa de privatizaciones trajo aparejado, hasta fines de 1993, un ingreso de recursos superior a los 15000 millones de dólares, de los cuales más de la tercera parte corresponde al valor de mercado de los títulos de la deuda

\footnotetext{
4 A los problemas macroeconómicos (elevados niveles de inflación, profundos desequilibrios fiscales, generalizada incertidumbre), se sumaron las deficitarias condiciones regulatorias, la necesaria inscripción en las negociaciones paralelas sobre la deuda externa y, en general, las lógicas inconsistencias causadas por haberse dado prioridad a la celeridad del proceso.
} 
pública externa e interna capitalizados en los distintos procesos.

Esa composición de los ingresos provenientes de las privatizaciones presenta marcadas discrepancias entre dos etapas claramente diferenciadas en la ejecución del programa, tanto en las metodologías y modalidades preferidas en cada caso como en su funcionalidad respecto del resto de las políticas públicas. Así, en la primera de esas etapas, que se extiende hasta el inicio del Plan de Convertibilidad (abril de 1991), el rescate de títulos de la deuda externa explica más del 85\% de los ingresos fiscales. En contraposición, en las privatizaciones concretadas entre abril de 1991 y diciembre de 1993 la capitalización de títulos de la deuda no alcanza a representar el $30 \%$ de los ingresos totales. ${ }^{5}$

Mientras que en la primera etapa se dio prelación a las transferencias globales, con una desatención casi total por la formulación de marcos regulatorios -no ajena a las urgencias políticas de la administración- 6 en la segunda fase se recurrió también, entre otras cosas, a la segmentación de las empresas que se privatizarían y a la oferta pública de acciones, al tiempo que se avanzó lentamente hacia la regulación de algunos de los servicios públicos privatizados.

Asimismo, en este último período la funcionalidad para con el programa de estabilización pasó a adquirir una dimensión distinta. La absorción por parte del Ministerio de Economía de las misiones y funciones del ex Ministerio de Obras y Servicios Públicos (en cuya órbita se agrupaba la mayor parte de las empresas públicas sujetas a privatización), la mejora en la situación fiscal de corto plazo, el sostén de la paridad cambiaria fija y la moderada recuperación de la inversión, emergieron como rasgos decisivos de esa funcionalidad.

\section{II}

\section{Los principales efectos macroeconómicos}

El desarrollo del programa de privatizaciones emprendido en la Argentina ha sufrido múltiples mutaciones de diversa naturaleza, lo que lleva a reflexionar sobre su impacto fiscal y sobre sus efectos, entre otros, en el sector externo, la estructura de precios relativos, la formación de capital y la regulación de oligopolios en ausencia de una legislación antimonopólica

\section{Los aspectos fiscales}

La aplicación del programa de privatización ha tenido impacto fiscal importante - por única vez- en los ingresos en efectivo que percibe el Estado por la transferencia de empresas o de tenencias accionarias. Asimismo, ha incorporado un nuevo rubro derivado de los futuros recursos tributarios que se originarán en el pago de impuestos -esencialmente sobre las ganancias- por los consorcios adjudicatarios de las firmas privatizadas.?

5 Las privatizaciones del área petrolera quedaron mayoritariamente incluidas en la segunda etapa y se trató, en todos los casos, de transferencias y concesiones adquiridas en efectivo.

6 Al decir de Gerchunoff (1992), "de un modo u otro los cambios debían ser realizados; bien o mal, había que privatizar".

7 Salvo unas pocas excepciones, las empresas públicas privatizadas no abonaban los impuestos devengados o no obtenían beneficios afectados por el impuesto a las ganancias.
Por otra parte, el Estado ha dejado de percibir diversos impuestos internos de asignación específica - como el correspondiente a la seguridad socialque gravaban los precios de determinados servicios públicos. En la generalidad de los casos, tales "sobreprecios" fueron absorbidos por el ajuste tarifario que acompañó a las privatizaciones y, por ende, transferidos a los adjudicatarios como parte de las tarifas.

Desde el punto de vista de los egresos fiscales, el Estado se ha visto beneficiado por la supresión de la incidencia de los déficit operativos de buena parte de las empresas públicas transferidas, así como también por la eliminación de los servicios de la deuda externa capitalizada en las privatizaciones. En contraposición, dado que en la generalidad de los casos el Estado se hizo cargo del endeudamiento de las empresas privatizadas, ${ }^{8}$ ello supone posteriores egresos fiscales por concepto de amortizaciones y servicios (cuadro 1).

\footnotetext{
8 Si bien, en la práctica, la Tesorería terminaría por hacerse cargo de las deudas contraidas por las empresas públicas, sus servicios y la casi totalidad de las deudas comerciales eran generalmente asumidas por las propias empresas. En otras palabras, de una situación inestable y heterogénea se pasó a una absorción lisa y llana de tal endeudamiento por parte del Estado.
} 
CUADRO 1

\begin{tabular}{lrrr}
\multicolumn{3}{c}{$\begin{array}{l}\text { Argentina: Endeudamiento de empresas públicas } \\
\text { privatizadas asumido por el Tesoro nacional } \\
\text { (Millones de pesos) }\end{array}$} \\
$\begin{array}{l}\text { Empresas } \\
\text { privatizadas }\end{array}$ & $\begin{array}{r} \\
\text { Deuda } \\
\text { externa }\end{array}$ & $\begin{array}{c}\text { Deuda } \\
\text { interna }\end{array}$ & Total \\
\hline Yacimientos Petrolíferos & & & \\
Fiscales (Y.P.F.) & 8786.6 & 7.2 & 8793.8 \\
Ferrocarriles & 1971.8 & 585.8 & 2557.6 \\
Gas del Estado & 1892.8 & 387.3 & 2280.1 \\
Hidronor & 1485.3 & 2.9 & 1488.2 \\
Somisa & 612.7 & 825.1 & 1437.8 \\
Agua y Energía Eléctrica & 328.3 & 729.8 & 1058.1 \\
Segba & 817.8 & 83.9 & 901.7 \\
E.L.M.A. & 406.3 & 329.9 & 736.2 \\
Caja Nac. de Ahorro y Seguros & -5 & 600.0 & 600.0 \\
Aerolíneas Argentinas & 421.3 & 6.4 & 427.7 \\
Entel & 269.6 & 26.4 & 296.0 \\
Obras Sanitarias de la Nación & 86.8 & 42.6 & 129.4 \\
Encotesa & 2.6 & 110.6 & 113.2 \\
& & & \\
Total & 17081.9 & 3737.9 & 20819.8 \\
\hline
\end{tabular}

Fuente: Elaborado sobre la base del Presupuesto Nacional de 1994.

De las consideraciones precedentes se infiere que, si bien es posible realizar ciertas aproximaciones en algunos ejemplos concretos, ${ }^{9}$ es difícil estimar con precisión el impacto fiscal global de las privatizaciones. En el plano agregado puede afirmarse que, en el corto plazo, el generalizado proceso de privatización tuvo un efecto positivo sobre las cuentas fiscales. Agotado ese primer impacto, derivado esencialmente de los ingresos en efectivo y de la supresión de los servicios de las deudas capitalizadas, las cuentas públicas se han visto crecientemente erosionadas por la incidencia de ciertos rubros - como los servicios de las deudas absorbidas por el Estado- que tienden a compensar en el mediano y largo plazo ese primer impacto positivo.

Más allá del efecto fiscal en términos de flujos de ingresos y egresos, cabe mencionar otros aspectos que - directa o indirectamente - están vinculados con tal impacto. Uno de ellos es la valoración de los activos que fueron transferidos al sector privado donde, en general, el valor presente de las rentas futuras resultó significativamente superior a los respectivos precios de transferencia de las empresas. En tal sentido,

\footnotetext{
9 Véase, por ejemplo, las estimaciones incorporadas en Gerchunoff (1992) acerca de ENTEL, de las rutas de alto tráfico y de las reservas petroleras. Sin embargo, tales estimaciones no contemplan, entre otros, el efecto fiscal derivado de la absorción estatal de los pasivos de las empresas o áreas privatizadas.
}

la subvaluación de los activos públicos privatizados ${ }^{10}$ estuvo asociada a la celeridad de los procesos y a la despreocupación oficial por la reestructuración y por el previo saneamiento tecnoproductivo, económico y financiero de las empresas que se privatizarían.

De todas maneras, al margen de la generalizada subvaluación de los activos estatales, los ingresos provenientes de las privatizaciones fueron un elemento clave para modificar la situación de las finanzas del sectorpúblico. ${ }^{11}$ En efecto, los recursos provenientes de las privatizaciones han asumido un papel protagónico en el reordenamiento de las cuentas fiscales, particularmente en los inicios del Plan de Convertibilidad, donde emergen como el sustento fundamental del necesario equilibrio fiscal. Así, en los últimos nueve meses de 1991, los ingresos derivados de las privatizaciones alcanzaron a representar casi el $80 \%$ del resultado total; proporción que decreció significativamente en los dos últimos años: $42.3 \%$ en 1992 y 20.9\% en 1993 (cuadro 2).

Ese menor aporte relativo de las privatizaciones al equilibrio fiscal no indica un saneamiento estructural que lo haga menos dependiente de los ingresos extraordinarios. Por el contrario, en la evolución de las cuentas públicas se manifiestan desequilibrios e insuficiencias que plantean serios interrogantes para cuando culmine el programa de privatizaciones. Así, desde el cuarto trimestre de 1992 y a lo largo de 1993 se registra un déficit en el resultado operativo de la Tesorería, como consecuencia de un estancamiento relativo de los ingresos corrientes y una creciente incidencia de los gastos totales, en particular los derivados de pagos por bienes y servicios. De allí que el resultado total positivo se origine en los ingresos no tributarios, es decir, en recursos extraordinarios.

$\mathrm{Si}$ estos ingresos extraordinarios no implican transformaciones que lleven a una mejora cierta y de largo plazo en las arcas fiscales, su impacto efectivo

\footnotetext{
${ }^{10}$ Por ejemplo, en el caso de ENTEL, las imprecisas valuaciones de la empresa cubrían un espectro que iba de los 1900 millones - precio definitivo por el que se transfirió- a los 3500 millones de dólares; numerosas áreas petroleras marginales (con una alta relación gas/petróleo) se transfirieron sin imputarle valor alguno al contenido gasífero.

${ }^{11}$ Si bien por Decreto 575/90 se estableció que los fondos provenientes de las privatizaciones se destinarían al gasto social, sucesivas excepciones derivaron - en la práctica - en el desconocimiento real de tales disposiciones. El ejemplo argentino resulta suficientemente ilustrativo del tratamiento del tema por Devlin (1993), quien al subrayar la importancia de asignar al gasto social los recursos extraordinarios derivados de las privatizaciones señala que "...puede ser difícil realizar asignaciones específicas en situaciones de urgencia fiscal generalizada".
} 
CUADRO 2

Argentina: Tesorería General de la Nación. Ingresos y egresos durante la aplicación del Plan de Convertibilidad, $2^{2}$ trimestre de 1991 a $4^{2}$ trimestre de 1993

(Millones de pesos de febrero de 1994)

\begin{tabular}{|c|c|c|c|c|c|c|c|c|}
\hline & $\begin{array}{c}\text { Ingresos } \\
\text { totales }\end{array}$ & $\begin{array}{l}\text { Ingresos } \\
\text { corrientes }\end{array}$ & $\begin{array}{c}\text { Otros } \\
\text { ingresos }\end{array}$ & $\begin{array}{l}\text { Gastos } \\
\text { totales }\end{array}$ & $\begin{array}{l}\text { Resultado } \\
\text { operativo }^{\text {a }}\end{array}$ & $\begin{array}{l}\text { Resultado } \\
\text { total } \mathrm{b}\end{array}$ & $\begin{array}{l}\text { Privati- } \\
\text { zaciones }\end{array}$ & $\begin{array}{l}\% \text { correspondiente a } \\
\text { privatizaciones en el } \\
\text { resultado total }\end{array}$ \\
\hline \multicolumn{9}{|l|}{1991} \\
\hline $2^{\circ}$ trim. & 3094 & 2508 & 586 & 2547 & -39 & 547 & 630 & 115.2 \\
\hline $3^{\circ}$ trim. & 3866 & 2579 & 1287 & 3497 & -918 & 369 & 134 & 36.3 \\
\hline $4^{\circ}$ trim. & 3469 & 2868 & 601 & 2865 & 3 & 604 & 430 & 71.2 \\
\hline \multicolumn{9}{|l|}{9 últimos } \\
\hline $\begin{array}{l}\text { meses } \\
1992\end{array}$ & 10429 & 7955 & 2474 & 8909 & -954 & 1520 & 1194 & 78.6 \\
\hline ler trim. & 3806 & 2896 & 910 & 2830 & 66 & 976 & 666 & 68.2 \\
\hline $2^{\circ}$ trim. & 3277 & 3025 & 252 & 2769 & 256 & 508 & 152 & 29.9 \\
\hline $3^{\circ}$ trim. & 3453 & 3126 & 327 & 2752 & 374 & 701 & 114 & 16.3 \\
\hline $4^{\circ}$ trim. & 3876 & 2705 & 1171 & 3367 & -662 & 509 & 208 & 40.9 \\
\hline Total & 14412 & 11752 & 2660 & 11718 & 34 & 2694 & 1140 & 42.3 \\
\hline \multicolumn{9}{|l|}{1993} \\
\hline ler trim. & 3224 & 2488 & 736 & 3038 & -550 & 186 & 4 & 2.2 \\
\hline $2^{\circ}$ trim. & 4015 & 2991 & 1024 & 3253 & -262 & 762 & 226 & 29.7 \\
\hline $3^{\circ}$ trim. & 4315 & 3312 & 1003 & 3395 & -83 & 920 & 155 & 16.8 \\
\hline $4^{\circ}$ trim. & 4116 & 3131 & 985 & 3160 & -29 & 956 & 204 & 21.3 \\
\hline Total & 15670 & 11922 & 3748 & 12846 & -924 & 2824 & 589 & 20.9 \\
\hline
\end{tabular}

Fuente: Elaboración propia basada en información de la Secretaría de Hacienda.

a Ingresos corrientes menos gastos operativos.

$\mathrm{b}$ Ingresos totales menos gastos totales.

tiende a diluirse por la persistencia de desequilibrios estructurales, e incluso por los costos implícitos del propio programa de privatización. ${ }^{12}$

\section{Efectos en el sector externo}

En el corto plazo, los ingresos de capitales derivados de los fondos que el Estado recibe en efectivo por la transferencia de sus empresas tienen un impacto positivo en la balanza de pagos. En el ejemplo argentino, esto contribuyó de manera decisiva ${ }^{13}$ a revertir una tendencia que se remontaba a más de dos décadas: las permanentes transferencias netas de capitales al exterior. En efecto, por primera vez en largos años, en el trienio 1990-1992 se registró un ingreso neto de divisas del orden de los 15000

\footnotetext{
12 Esto se ve reflejado en forma aún incipiente en la evolución y conformación de la estructura del gasto de la Tesorería de la Nación. Así, por ejemplo, el correspondiente a bienes y servicios se duplicó en apenas un bienio (1991-1993), con lo cual su incidencia en el total subió del $9.0 \%$ al $15.2 \%$ y explicó casi el $80 \%$ del aumento en el gasto total.

${ }^{13}$ Otra proporción importante del ingreso de recursos externos se origina en movimientos de corto plazo asociados a la vigencia de tasas de interés internas - en dólares- superiores a las internacionales.
}

millones de dólares (Argentina, Ministerio de Economía y Obras y Servicio Públicos, 1993), constituyéndose en factor decisivo para sostener la paridad cambiaria y compensar los déficit de la balanza comercial registrados en el período.

$\mathrm{Al}$ respecto, la información relativa a la cuenta de capital de la balanza de pagos permite comprobar que los ingresos asociados al programa de privatizaciones se elevaron considerablemente en el período 1990-1992; según las proyecciones oficiales, tenderán a estabilizarse en torno a los 4700 millones de dólares en el bienio 1993-1994, para comenzar a decrecer aceleradamente a partir de 1995.

El principal efecto positivo de las privatizaciones -el ingreso de capitales - , se verifica exclusivamente durante el proceso de "desestatización" de las empresas públicas. Sin embargo, a medida que éstas son transferidas al sector privado, toma forma otro efecto, de carácter permanente y signo contrario, sobre la balanza de pagos. Se trata de la remisión de utilidades y dividendos al exterior por parte de los consorcios adjudicatarios de las empresas privatizadas, la que, desde una perspectiva de mediano plazo, revela un crecimiento sostenido a partir de 1990, en consonancia con la consolidación de las operaciones de tales firmas (cuadro 3). 
CUADRO 3

Argentina: Balanza de pagos. Evolución de la inversión extranjera directa, a las privatizaciones y las remesas por concepto de utilidades y dividendos, 1988-1995.

(Millones de dólares)

\begin{tabular}{|c|c|c|c|}
\hline \multirow[b]{2}{*}{ Años } & \multicolumn{2}{|c|}{ Ingresos } & \multirow{2}{*}{$\begin{array}{c}\text { E g r e s o s } \\
\text { (Utilidades } \\
y \\
\text { dividendos) }\end{array}$} \\
\hline & $\begin{array}{c}\text { Inversión } \\
\text { extranjera } \\
\text { directa }\end{array}$ & $\begin{array}{l}\text { Privati- } \\
\text { zaciones }\end{array}$ & \\
\hline 1988 & 1147 & & -660 \\
\hline 1989 & 1028 & & -664 \\
\hline 1990 & 333 & 1703 & -716 \\
\hline 1991 & 465 & 1974 & -805 \\
\hline 1992 & 2852 & 1841 & -850 \\
\hline $1993^{b}$ & & & -945 \\
\hline $1994^{b}$ & & & -1407 \\
\hline $1995^{b}$ & & & -2057 \\
\hline
\end{tabular}

Fuente: Elaboración propia basada en información del Banco Central de la República Argentina (BCRA) y del Presupuesto Nacional 1994.

"La capitalización de títulos de la deuda externa en los distintos procesos de privatizaciones se computa en el rubro "Inversión extranjera directa", mientras que los ingresos derivados de los pagos en efectivo se asignan al rubro "Privatizaciones".

${ }^{\mathrm{b}}$ Proyecciones oficiales.

Este comportamiento de las remesas de utilidades y dividendos tiende a neutralizar el aporte inicial positivo de las privatizaciones a la balanza de pagos. Como su expansión se verifica en un marco macroeconómico interno y financiero internacional que desalienta la remisión de utilidades al exterior, ${ }^{14}$ sus efectos más comprometedores se registrarán recién en el mediano plazo, si se modifica alguno (o algunos) de los factores de ese contexto.

Otro importante efecto de las privatizaciones sobre la balanza de pagos surge de la supresión de los servicios de los títulos de la deuda externa que fueron capitalizados como parte de pago de las empresas transferidas al sector privado. Así, hasta fines de 1993, se privatizaron actividades estatales por un monto total de 23162 millones dedólares si se computa el rescate de bonos - de la deuda externa e interna- a su valor nominal, y de casi 15500 millones si se considera el valor efectivo de los mismos (66.9\% del

${ }^{14}$ Entre 1990 y 1992 la Libor a 180 días se redujo $57 \%$ (del $9.22 \%$ al $3.95 \%)$. anterior). El valor nominal de los títulos de la deuda pública que se rescataron a raíz del programa ascendió a 13400 millones de dólares, es decir, a un 58.0\% de los ingresos totales, y su valor efectivo fue de 5758 millones de dólares equivalentes al $42.9 \%$ del valor nominal (cuadro 4).

El rescate de bonos de la deuda externa tuvo un impacto inicial significativo en el monto acumulado del endeudamiento (se prevé que superará los 20000 millones de dólares al concluir el programa). La disminución de la deuda originada por la venta de los activos públicos (poco más de 11000 millones de dólares), equivalió al $19 \%$ de la deuda externa total de 1989. Sin embargo, esa disminución fue más que compensada por el nuevo endeudamiento en que se incurrió durante el período, con el cual el incremento neto de la deuda externa fue del orden de los 2700 millones de dólares entre 1989 y $1992 .{ }^{15}$ En otras palabras, a pesar de la incorporación de la Argentina

\footnotetext{
15 Aún más, la deuda externa pública, directamente afectada por las privatizaciones, se incrementó en 900 millones de dólares.
} 
Argentina: Resultado financiero del programa de privatizaciones, 1990-1993 (Millones de dólares)

\begin{tabular}{|c|c|c|c|c|c|c|}
\hline & \multirow[b]{2}{*}{ Efectivo } & \multicolumn{2}{|c|}{ Títulos } & \multirow{2}{*}{$\begin{array}{c}\text { Pasivos } \\
\text { transferidos }\end{array}$} & \multicolumn{2}{|c|}{ Totales } \\
\hline & & $\begin{array}{c}\text { Valor } \\
\text { nominal }\end{array}$ & $\begin{array}{c}\text { Valor } \\
\text { efectivo }\end{array}$ & & $\mathrm{A}^{\mathrm{a}}$ & $\mathrm{B}^{\mathrm{b}}$ \\
\hline Teléfonos & 2279.0 & 5029.0 & 1257.0 & - & 7308.0 & 3536.0 \\
\hline Aerolíneas & 190.1 & 1313.8 & 394.1 & - & 1503.9 & 584.2 \\
\hline Electricidad & 1283.1 & 2543.5 & 1836.0 & 460.7 & 3826.6 & 3579.8 \\
\hline Puertos & 13.3 & - & - & - & 13.3 & 13.3 \\
\hline Radio y TV & 13.9 & - & - & - & 13.9 & 13.9 \\
\hline Petróleo & 4846.8 & 1271.1 & 1080.4 & - & 6117.9 & 5927.2 \\
\hline Gas & 658.0 & 3082.1 & 1120.3 & 1110.0 & 3740.1 & 2888.3 \\
\hline Petroquímica & 53.3 & 132.0 & 46.0 & - & 185.3 & 99.3 \\
\hline Astilleros & 59.8 & - & - & - & 59.8 & 59.8 \\
\hline Siderurgia & 143.3 & 41.8 & 22.5 & - & 185.1 & 165.8 \\
\hline Inmuebles & 130.9 & - & - & - & 130.9 & 130.9 \\
\hline Otros & 65.2 & 12.0 & 2.0 & - & 77.2 & 67.2 \\
\hline Totales & 9736.7 & 13425.3 & 5758.3 & 1570.7 & 23162.0 & 15495.0 \\
\hline
\end{tabular}

Fuente: Elaboración propia basada en información del Ministerio de Economía y Obras y Servicios Públicos.

a Es el resultado de sumarle al efectivo y a los pasivos transferidos el valor nominal de los bonos rescatados.

${ }^{b}$ Es el resultado de sumarle al efectivo y a los pasivos transferidos el valor efectivo de los bonos rescatados.

al Plan Brady, la evolución del endeudamiento externo muestra que el efecto de la venta de las empresas públicas ha quedado neutralizado (cuadro 5).

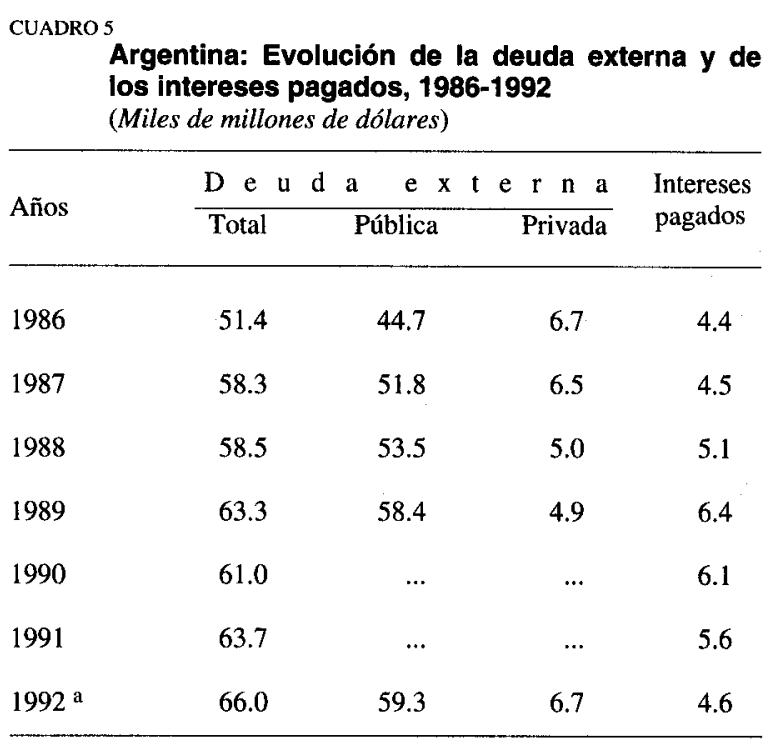

Fuente: Elaboración propia basada en información de la Oficina de la CEPAL en Buenos Aires.

a Estimación provisional
En ese incremento neto del endeudamiento externo subyace otro fenómeno que probablemente se acentuará en el futuro. Se trata de cambios en su composición que denotan el comienzo de un nuevo ciclo liderado por el sector privado, en general y, por los grupos empresarios que se adjudicaron las empresas privatizadas, en particular. A título ilustrativo, el valor de las obligaciones negociables emitidas por las firmas privadas hasta fines de 1993 ascendió a 3457 millones de dólares, lo que implica un incremento de 2701 millones de dólares durante dicho año; las obligaciones negociables autorizadas pero aún no emitidas fueron de 705 millones de dólares, y las solicitadas pero aún no autorizadas alcanzaron a 1700 millones de dólares (cuadro 6).

$\mathrm{El}$ análisis de las empresas que han emitido o están gestionando la colocación de obligaciones negociables permite inferir el grado de vinculación de este tipo de endeudamiento con las privatizaciones. Los consorcios adjudicatarios de las empresas privatizadas (Telefónica o Telecom, por ejemplo) y las firmas que participan en forma directa en algunas de ellas (Astra o Pérez Companc), concentran una proporción mayoritaria de las obligaciones emitidas, $(72 \%)$. Lo mismo ocurre con las obligaciones negociables autorizadas pero no emitidas, en las cuales las firmas citadas concentran el $71 \%$ del monto to- 


\begin{tabular}{|c|c|c|c|c|}
\hline \multirow{2}{*}{ CUA } & \multicolumn{4}{|c|}{$\begin{array}{l}\text { Argentina: Obligaciones negociables del sector privado a fines de } 1993 \\
\text { (Millones de dólares) }\end{array}$} \\
\hline & \multicolumn{3}{|c|}{ Obligaciones negociables } & \multirow[b]{2}{*}{ Total } \\
\hline Empresas & Emitidas & Autorizadas & Solicitadas & \\
\hline \multicolumn{5}{|c|}{ Vinculadas a privatizaciones: } \\
\hline TELECOM & 750 & & 500 & 1250 \\
\hline Pérez Companc & 600 & & & 600 \\
\hline Banco Galicia & 600 & & & 600 \\
\hline EDESUR & & 300 & & 300 \\
\hline Astra & & & 300 & 300 \\
\hline Acindar & & 200 & & 200 \\
\hline Telefónica & 150 & & 500 & 650 \\
\hline Comercial del Plata & & & 150 & 150 \\
\hline Siderca & & & 100 & 100 \\
\hline Loma Negra & 85 & & & 85 \\
\hline Bridas & 85 & & & 85 \\
\hline IMPSA & 60 & & & 60 \\
\hline TECPETROL & 60 & & & 60 \\
\hline Otras & 86 & & & 86 \\
\hline Subtotal & 2486 & 500 & 1550 & 4536 \\
\hline Otras & 971 & 205 & 150 & 1326 \\
\hline Total & 3457 & 705 & 1700 & 5862 \\
\hline
\end{tabular}

Fuente: Elaboración propia basada en información de la Comisión Nacional de Valores.

tal, y más aún, en las obligaciones todavía no autorizadas su participación se eleva al $91 \%$ del total (Basualdo, 1994).

\section{Efectos en la estructura de precios relativos}

La evolución de los precios reales de los servicios públicos transferidos al sector privado origina importantes cambios en la estructura de precios relativos de la economía. Estas tendencias se han visto potenciadas por su convergencia con las políticas de desregulación de mercados y de apertura de la economía: el grado en que los bienes y servicios son transables en el exterior pasa a explicar, en gran medida, el comportamiento de sus respectivos precios.

Hay diversos casos de ajustes que superan holgadamente el ritmo de crecimiento de la mayor parte de los restantes precios de la economía. ${ }^{16}$ A ello se agrega, muy particularmente en el área de los energéticos, una creciente dispersión de las estructuras tari-

\footnotetext{
16 En algunos casos (como los de ENTEL o Aerolíneas Argentinas), el ajuste de las tarifas se hizo efectivo con anterioridad a la transferencia al sector privado - como forma de atraer a los potenciales interesados-, incluyendo cláusulas contractuales con garantía de precios reales; mientras que en otros (electricidad, gas), los mayores incrementos relativos se verificaron a partir de la administración privada de las consiguientes empresas prestatarias de los servicios.
}

farias y, por otro lado, diferencias considerables en la evolución real de los precios de los distintos servicios. $^{17}$

La configuración de una nueva estructura de precios relativos que tiende a favorecer a las áreas privatizadas proveedoras de servicios en detrimento de los sectores productores de bienes transables no protegidos, se ve reflejada en los patrones de comportamiento de las distintas actividades económicas. Al respecto, un estudio de la Unión Industrial Argentina (Coloma, 1993) permite comprobar que tanto por la evolución de las ventas como, fundamentalmente, por los respectivos márgenes de rentabilidad, las empresas que exhiben los mejores indicadores de desempeño son aquellas emergentes de privatizaciones, al tiempo que las productoras de bienes transables no protegidos son las que muestran los mayores niveles de deterioro relativo, cualquiera sea la variable que se considere. (En una situación intermedia quedan las empresas productoras de bienes protegidos natural o normativamente).

Debe señalarse que en todas aquellas áreas en las que los consorcios adjudicatarios de las empresas

\footnotetext{
17 En la generalidad de los casos (en especial en el campo energético), los incrementos de las tarifas para los grandes usuarios han tendido a ubicarse bastante por debajo de los niveles medios, y más aún de los niveles tarifarios para consumos residenciales.
} 
privatizadas cuentan con un poder decisivo en la fijación y actualización de las tarifas, el Estado no sólo transfirió los respectivos activos sino también la capacidad de influir en la estructura de precios relativos de la economía. En otras palabras, hubo un desplazamiento de los mecanismos de mercado ${ }^{18} \mathrm{y}$, a la vez, desde la perspectiva oficial, de las posibilidades de desplegar políticas públicas regulatorias o inductoras de determinadas actividades privadas. La transferencia de un usual instrumento de política económica supone, a la vez, la cesión a determinados segmentos del sector privado (que gozan de posiciones oligopólicas o monopólicas, preservadas legal o naturalmente, bajo condiciones de reserva de mercado) de buena parte del poder regulatorio sobre mercados que asumen un papel protagónico en la competitividad de la economía en su conjunto.

\section{Efectos en la inversión}

De acuerdo con los objetivos del programa de privatizaciones, el estímulo a la formación de capital es a la vez uno de sus principales fundamentos y uno de los resultados básicos esperados, teniendo en cuenta la desinversión observada en la mayor parte de las empresas sujetas a privatización.

Cabe reconocer aquí dos grandes componentes: en primer término, la formación de capital que realizarían los consorcios adjudicatarios (en parte comprometida formalmente) y, por otro lado, el efecto multiplicador potencial de ella.

En cuanto a lo primero, las estimaciones realizadas revelan que el efecto sobre la inversión agregada es moderado. De considerar la formación de capital que se derivaría de un amplio grupo de áreas privatizadas (gas, teléfonos, electricidad, ferrocarriles, trenes subterráneos, vialidad, puertos, aguas y servicios cloacales), la inversión agregada resultante equivaldría a poco más del $2 \%$ del producto interno bruto hasta mediados de los años noventa, para luego estabilizarse en torno al 1.5\% hasta fines de la década (FIEL, 1992). Por su parte, según las estimaciones oficiales, las inversiones comprometidas en empresas públicas privatizadas o entregadas en concesión se ubicarían, en 1994,

\footnotetext{
18 Por ejemplo, aunque en algunos pocos casos (gas, electricidad) se hace explícita la prohibición de "subsidios cruzados", la inexistencia de mecanismos regulatorios o al menos de criterios mínimos en la materia impiden toda acción restrictiva. Al respecto, la posibilidad de celebrar contratos específicos entre la empresa prestadora y la usuaria de los servicios hace viable, en caso de estar integradas en un mismo conglomerado, la recurrencia a precios de transferencia.
}

en torno al 1.0\% del PIB para decrecer, ya en 1995, a apenas el $0.8 \%$ del PIB (Argentina, Poder Ejecutivo Nacional, 1993). Tales montos de inversión ascenderían, según las proyecciones oficiales, a un promedio anual cercano a los 2600 millones de dólares en el trienio 1993-1995; esta cifra representaría apenas las dos terceras partes de la formación de capital realizada por las empresas públicas - siempre como promedio anual-durante el trienio 1980-1982, y sólo el 54.6\% de la correspondiente al trienio 1986-1988 (FIEL, 1992).

Aún cuando la inversión en las áreas privatizadas se ubicó por debajo de los valores medios durante la mayor parte de los años ochenta, tal formación de capital supuso un ligero incremento respecto de los bajos niveles registrados en los años inmediatamente anteriores. Esto se asocia, por un lado, a la aguda y generalizada desinversión de las empresas públicas en los años previos a su privatización y, por otro, a las necesidades de reacondicionamiento y mantenimiento de los servicios privatizados.

En tal sentido, a corto plazo se verifica un impacto positivo en la inversión agregada que, sin embargo, ve amortiguados sus efectos multiplicadores locales por el alto componente de equipamiento adquirido en el exterior (como en el caso de las telecomunicaciones) y queda circunscrito a un número reducido de sectores de actividad.

Por último, en tanto las actividades más dinámicas en términos de ventas y rentabilidad son las protegidas de la competencia externa y las prestadoras de los servicios recientemente privatizados, la formación de capital tiende a reproducir y consolidar tal configuración. En ese marco, se desincentiva la inversión en la mayor parte de los sectores productores de bienes, frente a las opciones que ofrecen los procesos de privatización de empresas públicas, buena parte de los servicios $\mathrm{y}$, en general, las actividades asociadas a bienes y servicios no transables con el exterior. De allí que en términos de la competitividad internacional de la economía argentina sólo cabría esperar que las mejoras en la productividad de las empresas privatizadas con el tiempo se transfieran, a través de reducciones de costos, al resto de la economía y especialmente a los sectores que producen bienes exportables.

\section{Efectos en la oligopolización y conglomeración de la economía}

Otro rasgo sobresaliente del programa de privatizaciones es su papel propulsor de la concentración y 
centralización del capital. En la mayoría de los procesos concluidos en el país, el propio llamado a licitación favoreció la presencia de pocos oferentes, lo que se reforzó, en la generalidad de los casos, por la coordinación y el cabildeo empresarial en torno a sus respectivas ofertas. Esto llevó, por un lado, a una acentuada concentración de la propiedad de las empresas y de las áreas "desestatizadas" en un reducido número de grandes agentes económicos. ${ }^{19} \mathrm{Y}$ por otro, a la sobrevivenciay reforzamiento de monopolios - $-\mathrm{u}$ oligopolios- legales, con la consiguiente consolidación de mercados protegidos, en condiciones que aseguran bajos o nulos riesgos empresariales, y amplios márgenes de libertad para la fijación de tarifas. En este sentido, se observa - en comparación con otras experiencias internacionales - que ha habido escasa preocupación oficial por la difusión de la propiedad a través del mercado de capitales. ${ }^{20}$

Esa profundización del proceso de concentración del capital asociado a las privatizaciones de empresas públicas refleja, asimismo, la consolidación de una tendencia que se remonta a mediados de los años setenta: la asociación entre los grandes grupos económicos locales con firmas de capital extranjero. En la generalidad de los casos, tales asociaciones incluyen: grandes conglomerados de capital nacional que aportan capacidad gerencial y de cabildeo interno; bancos extranjeros o locales y contratistas públicos que han capitalizado títulos de la deuda -externa o interna-, y ciertas empresas transnacionales que generalmente aportan capacidad y experiencia tecnológica y de gestión.

En otras palabras, las modalidades de los diversos procesos de privatización -exigencias patrimoniales, requisitos técnicos, celeridad, importancia del poder de cabildeo, etc. - han facilitado e incluso inducido, el despliegue de estrategias por parte de los principales conglomerados locales, inscritas en una creciente polarización del poder económico. Al respecto, estilizando el análisis, se podría establecer una tipología - no excluyente - de estrategias empresa-

\footnotetext{
${ }^{19}$ Se trata, mayoritariamente, de los mismos conglomerados de capital nacional y extranjero que en años precedentes internalizaron las transferencias en aquellas áreas que, en forma discontinua, fueron privilegiadas por las políticas públicas (promoción industrial, estatización de la deuda externa, compras del Estado, etc.). ${ }^{20}$ Por el contrario, en la generalidad de los casos se fijaron patrimonios mínimos - muy elevados- para poder participar de las licitaciones o, en su defecto, tales montos patrimoniales eran una de las variables principales para la precalificación $o$ adjudicación. En otras palabras, la capacidad patrimonial de los potenciales interesados se convirtió, de hecho, en la principal barrera para ingresar al mercado de las privatizaciones de empresas públicas.
}

riales en la adquisición de la mayor parte de los activos del sector público:

i) Hubo grupos económicos que a través de alguna de sus empresas controladas adquirieron empresas públicas o acciones del Estado en firmas que operan en el mismo sector de actividad en el cual están insertos (concentración). Tal es el caso, por ejemplo, del grupo Indupa y su participación en Petropol S.A. e Induclor S.A.; del grupo Garovaglio y Zorraquín respecto a Polisur S.A., o del conglomerado Techint al adquirir la mayoría accionaria de SOMISA. Idéntico fenómeno se manifiesta en la privatización de áreas de explotación petrolífera que, en su mayoría, pasaron a manos de las principales empresas del sector;

ii) Hubo conglomerados empresariales que adquirieron $\mathrm{u}$ obtuvieron la concesión de empresas o servicios públicos para lograr, directa o indirectamente, un mayor grado de integración vertical u horizontal (integración). Los ejemplos son muchos: las siderúrgicas de Techint y Acindar que integran la producción y distribución de energía eléctrica y gas, insumos fundamentales de su producción; las principales empresas aceiteras (Bunge y Born, Cía. Continental, La Plata Cereal, La Necochea Quequén, etc.) en lo atinente a ferrocarriles e instalaciones portuarias; los oligopolios cementeros en ferrocarriles; las proveedoras de ENTEL en la privatización de dicha empresa -los grupos Pérez Companc (PECOM-NEC) y Techint (Telettra e Italtel)-; las empresas petroleras que pasan a controlar refinerías, destilerías, oleoductos, instalaciones portuarias, flota, etc.;

iii) Hubo grupos económicos que tuvieron una activa y difundida presencia (diversificación y conglomeración) en los distintos procesos de privatización. Basta con señalar el grupo Pérez Companc (generación y distribución de energía eléctrica, transporte y distribución de gas, explotación de petróleo, refinerías y destilerías, ferrocarriles, telecomunicaciones, etc.); el grupo Techint (distribución de energía eléctrica, explotación petrolífera, transporte de gas, ferrocarriles, telecomunicaciones, rutas camineras, industria siderúrgica, etc.) o el grupo Cía. General de Combustibles (generación de energía eléctrica, explotación petrolífera y destilerías, ferrocarriles, telecomunicaciones, aguas y servicios cloacales, etc.). El cuadro 7 presenta una síntesis de los consorcios en los que participan algunos de los principales conglomerados que operan en el país.

Sin duda, de esta tipología de estrategias empresariales frente al programa de privatizaciones se desprende que la creciente oligopolización y conglome- 
CUADRO 7

Argentina: Presencia de los principales grupos económicos en el programa de privatizaciones, por sectores de actividad (Millones de dólares)

\begin{tabular}{|c|c|c|c|c|c|c|c|}
\hline $\begin{array}{c}\text { Grupos } \\
\text { económicos }\end{array}$ & Electricidad & Gas natural & Petróleo & Ferrocarriles & Telefonía & $\begin{array}{c}\text { Industria } \\
\text { manufacturera }\end{array}$ & Otras \\
\hline Pérez Companc & $\begin{array}{l}\text { - Central Costanera } \\
\text { (generación) } 90.1 \text { millones } \\
\text { - TRANSENER } \\
\text { (transmisión de alta tensión) } \\
234.1 \text { millones } \\
\text { - EDESUR (distribución) } \\
511.0 \text { millones }\end{array}$ & $\begin{array}{l}\text { - Transportadora Gas del Sur } \\
\text { (transporte) } \\
356.2 \text { millones } \\
\text { - Distribuidora de Gas } \\
\text { Metropolitana (distribución) } \\
300 \text { millones }\end{array}$ & $\begin{array}{l}\text { - Areas Centrales: } \\
\text { Peesto Hemández (240.8 millones) } \\
\text { Santa Cruz II (141.6 millones) } \\
\text { - Areas Secundarias: } \\
\text { 11 arreas (70.2 millones) } \\
\text { - Refineria Campo Durán } \\
\text { (64.1 millones) } \\
\text { - Desilierí San Lorenzo } \\
\text { (12.2 millones) } \\
\text { - Term. Marít. Patagónicas } \\
\text { (10.1 millones) } \\
\text { - Oleoducto del Valle } \\
\text { (77.0 millones) }\end{array}$ & $\begin{array}{l}\text { - Ferroexpreso Pampeano } \\
\text { (concesión } 5.287 \mathrm{~km} \text {.) }\end{array}$ & $\begin{array}{l}\text { - TELECOM Argentina } \\
677 \text { millones } \\
\text { - Telefónica Argentina } \\
794 \text { millones }\end{array}$ & & \\
\hline TECHINT & $\begin{array}{l}\text { - EDELAP (distribución) } \\
139.0 \text { millones }\end{array}$ & $\begin{array}{l}\text { - Transportadora Gas del Norte } \\
\text { (transporte) } 210.2 \text { millones }\end{array}$ & $\begin{array}{l}\text { - Areas Centrales: } \\
\text { Tordillo (100.9 millones) } \\
\text { Aguarague (143.7 millones) } \\
\text { - Areas secundarias: } \\
10 \text { áreas (39.5 millones) } \\
\text { - Term. Marit. Patagónicas } \\
\text { (10.1 millones) } \\
\text { - Oleoducto del Valle } \\
\text { (77.0 millones) }\end{array}$ & $\begin{array}{l}\text { - Ferroexpreso Pampeano } \\
\text { (concesión } 5.287 \text { km.) }\end{array}$ & $\begin{array}{l}\text { - Telefónica Argentina } \\
794 \text { millones }\end{array}$ & $\begin{array}{l}\text { - somisA } \\
\text { (Siderurgia integral) } \\
\quad 147.2 \text { milones }\end{array}$ & $\begin{array}{l}\text { - Varias rutas nacionales } \\
\text { (concesión) } \\
\text { - Elevador portuario de } \\
\text { granos Ingeniero White } \\
\text { (concesión) }\end{array}$ \\
\hline ASTRA & $\begin{array}{l}\text { - EDENOR (distribución) } \\
427.9 \text { millones }\end{array}$ & $\begin{array}{l}\text { - Distribuidora de Gas } \\
\text { Metropolitana (distribuición) } \\
300 \text { millones }\end{array}$ & $\begin{array}{l}\text { - Areas centrales: } \\
\text { Vizcacheras (174.0 millones) } \\
\text { Santa Cruz II (141.6 millones) } \\
\text { - Areas secundarias: } \\
6 \text { áreas (24.9 millones) } \\
\text { - Trans. Maŕtim. Petrolero } \\
\text { (41.8 millones) } \\
\text { - Refinería Campo Durán } \\
\text { (64.1 millones) } \\
\text { - Term. Marít. Patagónicas } \\
\text { (10.1 millones) } \\
\text { - Oleoducto del Valle } \\
\text { (77.0 millones) }\end{array}$ & & & & \\
\hline $\begin{array}{l}\text { Compañía } \\
\text { General de } \\
\text { Combustibles } \\
\text { (Grupo Soldati) }\end{array}$ & $\begin{array}{l}\text { - Central Guemes } \\
\text { (generación) } 86.2 \text { millones }\end{array}$ & $\begin{array}{l}\text { - Transporadora Gas del Norte } \\
\text { (transporte) } 210.2 \text { millones } \\
\text { - Distribuidora de Gas } \\
\text { Metropolitana (distribuición) } \\
300 \text { millones }\end{array}$ & $\begin{array}{l}\text { - Areas centrales: } \\
\text { Palmar Largo ( } 36.0 \text { millones) } \\
\text { Santa Cruz I ( } 55.0 \text { millones) } \\
\text { Aguarague NO (143.7 millones) } \\
\text { - Areas secundarias } \\
\text { 3 áreas (1.3 millones) } \\
\text { - Interpertol (comercializadora) } \\
8.7 \text { millones }\end{array}$ & $\begin{array}{l}\text { - Ferroexpreso Pampeano } \\
\text { (concesión } 5.287 \mathrm{~km} \text {.) } \\
\text { - Ramal Delta-Borges } \\
\text { (concesión) }\end{array}$ & $\begin{array}{l}\cdot \text { Telefónica Argentina } \\
794 \text { millones }\end{array}$ & $\begin{array}{l}\text { - Destilería Dock Sur } \\
11.7 \text { millones } \\
\text { - Destilería S. Lorenzo } \\
12.2 \text { millones }\end{array}$ & $\begin{array}{l}\text { - Elevador portuario de } \\
\text { granos Ingeniero White } \\
\text { (concesión) } \\
\text { - Obras sanitarias de la } \\
\text { Nación (concesión) } \\
\text { - Canal 11 de T.V. } \\
\text { (concesión) } 8.2 \text { millones }\end{array}$ \\
\hline $\begin{array}{l}\text { SoCMA } \\
\text { (Grupo Macri) }\end{array}$ & & $\begin{array}{l}\text { - Distribuidora Gas del Centro } \\
\text { (distribuición) } 138 \text { millones } \\
\text { - Distrubuidora Gas Cuyana } \\
\text { (distribuición) } 122 \text { millones }\end{array}$ & $\begin{array}{l}\text { - Areas centrales: } \\
\text { Palma Largo (36.0 millones) } \\
\text { - Areas secundarias } \\
9 \text { áreas (18.5 millones) } \\
\text { - Refinería Campo Durán } \\
\text { (64.1 millones) }\end{array}$ & & & & $\begin{array}{l}\text { - Varias rutas nacionales } \\
\text { (concesión) } \\
\text { - Red acceso norte } \\
\text { (concesión) }\end{array}$ \\
\hline
\end{tabular}


ración de la economía argentina, y la consolidación y preservación de reservas de mercado con cuasi rentas oligopólicas emergen como algunos de los principales efectos de la aplicación de dicho programa. ${ }^{21}$

Más allá de sus connotaciones macroeconómicas y sociales, lo anterior incorpora rigideces y limitaciones adicionales al ámbito estricto de las áreas o mercados privatizados, como ser: i) el incremento del riesgo de captura o cooptación de los entes reguladores; ii) la introducción de serias distorsiones a una asignación socialmente eficiente de los recursos, al incorporar imperfecciones de mercado que, por ejemplo, se reflejan en las políticas de determinación de precios y tarifas (precios de transferencia entre em- presas proveedoras y consumidoras pertenecientes a un mismo grupo empresarial); iii) la generación de nuevas barreras a la entrada en el mercado de las privatizaciones, además de las que, en la generalidad de los casos, derivan de la propia naturaleza o de los marcos regulatorios de las actividades o áreas privatizadas, y iv) la erosión de niveles de competencia que de partida eran bastante bajos.

En síntesis, la escasa preocupación oficial por difundir la propiedad de las empresas privatizadas devino en efectos agregados de concentración de capital que, a su vez, atentan contra el propio desenvolvimiento competitivo de los mercados afectados por los procesos de privatización.

\section{III}

\section{La racionalidad en la privatización y regulación de los servicios públicos}

En esta sección se abordan dos temas íntimamente asociados. Por un lado, se analizan algunas cuestiones vinculadas a la racionalidad económica del programa de privatizaciones; por otro, se evalúan los rasgos que caracterizan el ejercicio del poder regulatorio sobre los servicios públicos privatizados.

\section{La racionalidad "limitada" de las privatizaciones}

En general, los argumentos utilizados para justificar una política de privatizaciones se basan en la convicción de que la libre competencia en o por los mercados es un eficaz asignador de recursos. En el caso de mercados naturalmente monopólicos, como la mayoría de los servicios públicos, se supone que un sistema de regulaciones o de subsidios adecuados, o de ambas cosas a la vez, inducirá comportamientos microeconómicos eficientes bajo un régimen de propiedad y administración privada.

En los hechos, sin embargo, la evaluación de la eficiencia de una organización cualquiera dependerá esencialmente de la definición de metas y de las restricciones que condicionen sus operaciones. Frecuentemente,

${ }^{21}$ Esto tiende a consolidar ciertos patrones de comportamiento empresarial cada vez más ajenos a la inversión de riesgo, la incorporación de progreso técnico, la innovación, la cualificación de la propia gestión, etc. la sustitución del objetivo de "bienestar social" por la maximización privada de beneficios conlleva complicaciones, puesto que los resultados finales no son independientes del proceso de interacción de los agentes económicos involucrados. (Véase Coloma, 1992; un modelo más completo puede hallarse en Piffano, 1991.)

Por ejemplo, es posible que en una empresa pública en la cual el poder de decisión se halla concentrado en agentes gubernamentales que buscan maximizar el excedente de los consumidores, el nivel de precios tienda a ubicarse por debajo del de otra en la cual los gerentes se "asocien" con los proveedores externos o con las burocracias sindicales.

Desde el punto de vista microeconómico, se espera que las decisiones de los gerentes profesionales a los que se estimula a maximizar las ganancias de los accionistas privados deberían redundar en reducciones del grado de ineficiencia. En los hechos, la vía para mejorar la productividad en las organizaciones prestadoras suele comenzar por una reducción del empleo, cambios en el perfil de calificaciones del personal retenido, y la implantación de una "cultura" más competitiva y "orientada al cliente". Sólo después se efectuarán inversiones en activos fijos productivos. Estos cambios no garantizan, sin embargo, más que una mejora relativa por sobre los niveles de prestación previa. Para converger a los estándares de la 
"mejor práctica" internacional se requieren otras dos condiciones: organismos regulatorios efectivos y capitalistas dispuestos a asumir los riesgos implícitos.

Sin duda, la racionalidad macroeconómica de las privatizaciones está íntimamente asociada a sus efectos sobre el crecimiento económico y la distribución del ingreso (Canovese y Rozenwurcell, 1991). En general, la privatización de empresas públicas elevará la tasa de crecimiento del producto sólo si eleva la tasa de inversión global. Sin embargo, en el caso argentino, el financiamiento de las inversiones ha provenido principalmente de los beneficios extraordinarios generados mediante la fijación de precios superiores a los compatibles con rentabilidades ordinarias. En función del patrón social de consumo de los servicios públicos, las mejoras en la tasa de crecimiento derivarían así, en última instancia, de cambios regresivos en la distribución del ingreso.

También se suele suponer que la inversión pública es menos eficiente que la privada, puesto que aquélla suele verse distorsionada por presiones extraeconómicas. Sin embargo, no está demostrado que en la economía argentina la propensión a la reinversión se comporte según el modelo teórico (Azpiazu, Vispo y Fuchs, 1993); los ingresos derivados de los frecuentes sistemas de subsidios cruzados no han generado la misma proporción de ahorro interno $\mathrm{y}$, por ende, no han significado incrementos equivalentes en el acervo de capital productivo.

Por otra parte, dada la estructura socioeconómica del país, la disposición escasamente schumpeteriana de su empresariado (Nochteff, 1993), y las particularidades del proceso privatizador argentino, la primera consecuencia de un esquema de este tipo sería una mayor concentración del poder económico. La funcionalidad de este proceso centralizador no ha sido demostrada por las autoridades, arriesgándose así cierta pérdida de credibilidad y apoyo social para la transformación. ${ }^{22}$

\section{Algunas características de la regulación de mo- nopolios naturales}

Así como la teoría económica reconoce la existencia de fallas del mercado y de problemas en la interven-

\footnotetext{
22 De hecho, una política de atomización de la propiedad, tal como la utilizada en Gran Bretaña, diluye la validez de este cuestionamiento basado en principios de eficiencia de largo plazo y de equidad. Si, por el contrario, se opta por una estrategia concentradora, se reduce la transparencia de los mercados y se estimulan comportamientos de diversificación y oligopolización.
}

ción pública, también identifica los riesgos característicos de la regulación de los servicios públicos privatizados. De los factores señalados en la teoría se analizarán solamente dos que muestran una cierta relación de refuerzo mutuo.

\section{a) Asimetrias de información}

Estas asimetrías pertenecen a la clase de problemas encarados por la teoría del dilema propietarioagente (principal-agent) y surgen cuando los datos críticos son de difícil observación. El agente supervisor -en este caso el regulador- debe diseñar sistemas de incentivos que aseguren, con el menor costo de seguimiento posible, que la información ofrecida sea confiable y a la vez que las decisiones respeten los objetivos convenidos. En general, para los reguladores también habrá asimetrías de información respecto de la rentabilidad de las inversiones, los efectos de la incorporación de nuevas tecnologías, los esfuerzos centrados en la minimización de los costos, el cálculo de subsidios que garanticen una cantidad de prestaciones socialmente óptimas, y otros aspectos. ${ }^{23}$

Si bien la responsabilidad primaria de los entes reguladores suele concentrarse en el seguimiento de los precios y la calidad de las prestaciones convenidas, en el caso de los monopolios naturales es frecuente que se requieran importantes inversiones de capital (en telecomunicaciones, agua potable, gas, etc.) que también deberán ser supervisadas. ${ }^{24} \mathrm{~A}$ su vez, muchas de estas inversiones serán una "barrera a la entrada" de nuevos oferentes. El Estado debe asegurar tanto la atención de las futuras demandas como una actualización tecnológica razonable. ${ }^{25}$

Para controlar la ejecución de las inversiones es preciso también disponer de información pertinente.

\footnotetext{
23 En el ejemplo argentino, la capacidad de seguimiento y negociación de los entes reguladores quedó fuertemente restringida durante los propios procesos de privatización. Durante ese período hubo interrupción, desarticulación, y en muchas ocasiones, "privatización" y desmantelamiento de importantes archivos históricos de información básica (energía, transporte, puertos).

24 Téngase presente que una de las justificaciones centrales del proceso de privatizaciones fue la insuficiencia de las inversiones públicas en las redes de servicios. Estas redes mostraban un deterioro significativo por deficiencias de mantenimiento $y$, en algunos casos, estaban cercanas al fin de su vida útil (ciertos troncales de la red de agua potable) o requerían el salto a una nueva generación tecnológica (centrales telefónicas digitales).

25 Por ejemplo, cabe preguntarse cuáles serían las consecuencias de largo plazo de fijar los precios de la electricidad (es decir, las tarifas al nivel del generador térmico menos eficiente), basándose en estimaciones de costo marginal que no garanticen las significativas inversiones requeridas para atender el crecimiento de la demanda más allá del año 2000 .
} 
Cada esquema tiene sus rasgos específicos: si al regular la prestación se admite una rentabilidad determinada, se alienta la sobrecapitalización para incrementar las utilidades; en cambio, una fórmula de ajuste por el índice de precios menos un factor de corrección deriva en una menor calidad de servicio y en subinversión.

El problema es aún más complejo cuando se trata de productos múltiples o se fijan marcos tarifarios para el futuro, puesto que el regulador no podrá observar muchas de las variables en forma directa. En estos casos, es difícil evitar que surjan situaciones de discriminación y, eventualmente, de subsidios cruzados.

Por último, mientras que la teoría económica capta exclusivamente una "asimetría de buena fé" derivada de la complejidad técnica de las actividades inspeccionadas, en el caso argentino involucra un fenómeno más amplio, que podría denominarse la asimetría por "renuncia" del Estado. ${ }^{26}$

\section{b) Cooptación del agente regulador}

Otro de los puntos críticos de un sistema regulatorio es la naturaleza de la relación entre los agentes reguladores y las empresas. En estos casos una frecuente interacción entre ambas partes puede tornar al regulador más permeable a los intereses de la firma. La duración del funcionario en el cargo, el nivel de remuneración, las perspectivas de obtener cargos importantes dentro del sector controlado, entre otros aspectos, influyen decisivamente en el grado de independencia de criterio del regulador $y$, por ende, en la eficacia del sistema regulatorio.

Asimismo, es posible que los funcionarios de los entes reguladores resulten sensibles a las presiones de los niveles jerárquicos políticos del gobierno que los designa. En este sentido, y dadas la celeridad e improvisación de algunas de las privatizaciones realizadas en el país, la autoridad de los reguladores ha quedado debilitada por decisiones previas orientadas a satisfacer los objetivos políticos gubernamentales.

En líneas generales, parece aconsejable que los mecanismos regulatorios mantengan la máxima credibilidad posible, acotando la discrecionalidad de los agentes reguladores dentro de un marco legal que provea instrumentos de inspección y sanción suficien-

${ }^{26}$ Como, por ejemplo, la incapacidad para verificar el cumplimiento del actual régimen de la industria automotriz; o la posesión por parte de agentes privados de los catastros urbanos de la Capital Federal con la zonificación que identifica las posibilidades de explotación comercial (la copia maestra de dichos registros "desapareció" en un incendio). tes. Dado que la regulación de los servicios públicos privatizados plantea complejos problemas tanto conceptuales como prácticos, es preciso contar con una legislación transparente y con un cuerpo técnico idóneo y facultado para recabar la información básica a fin de poder actuar con independencia. Cuando no se verifica la condición de autonomía, tanto respecto de los empresarios como de los funcionarios gubernamentales, el sistema continúa dependiendo de decisiones asociadas a determinados proyectos políticos, y se invalida así otro de los postulados que sustentan un programa de privatizaciones "racional". ${ }^{27}$

En síntesis, a partir de las condiciones identificadas por Devlin (1993), puede concluirse que el proceso de privatizaciones argentino no se ha caracterizado por la transparencia. En este sentido, no se han instalado mecanismos que minimicen la asimetría de la información con que opera el regulador. Tampoco se ha respetado el principio republicano de publicidad de los actos de gobierno, puesto que el acceso a los contratos de concesión y a las resoluciones de los entes (documentación relevante dado su potencial para "interpretar" las leyes marcos) permanece restringido al público $\mathrm{y}$, con frecuencia, a los propios representantes de diversos organismos de gobierno. ${ }^{28}$

\section{Los organismos contralores de los servicios públicos privatizados}

Las funciones de regulación del Estado se definen como aquel conjunto de atribuciones e instrumentos necesarios para el seguimiento y supervisión del cumplimiento de normas impuestas en beneficio de la comunidad (control ambiental, seguridad de tránsito, etc.), incluyendo la prestación de servicios públicos transferidos al sector privado. Estas funciones de regulación son indelegables, ya que están orientadas a preservar el bien común.

En el país, la función de regulación con frecuencia estuvo depositada implícitamente en las mismas empresas y organismos responsables de la provisión del servicio, lo que generó un sistema de responsabilidades bastante difuso. Así, sólo a partir de la privatización de los servicios públicos se introdujo en el

\footnotetext{
${ }^{27}$ Existen numerosos ejemplos de esta cooptación bifronte; por ejemplo, el intento de apropiación del fondo estabilizador del precio spot de la electricidad para aplicar recursos a obras de infraestructura en una provincia intervenida por el gobierno federal fue convalidado por el Ente Regulador de la Electricidad (ENRE).

${ }^{28}$ Ejemplo de esto último es el esfuerzo desplegado por el Ministerio de Economía para impedir que la Auditoría General de la Nación supervise a las empresas recientemente privatizadas.
} 
escenario económico institucional argentino la figura explícita de los entes de regulación, ${ }^{29}$ orientados a proteger los derechos del consumidor y a promover la competencia donde ésta resulte posible.

\section{a) Los entes reguladores}

Los entes reguladores de los servicios públicos privatizados constituyen hasta la fecha una colección de experiencias inconexas, en distintas etapas de evolución. Una tipología preliminar en función del grado de maduración de cada proceso y de la eficacia alcanzada, permite distinguir lo siguiente:

i) Entes con capacidad formal de regulación: Ellos son la Comisión Nacional de Telecomunicaciones (CNT), el Ente Regulador de la Electricidad (ENRE), el Ente Nacional Regulador del Gas (ENARGAS), y el Ente Tripartito de Obras y Servicos Sanitarios (ETOSS). ${ }^{30} \mathrm{La}$ CNT nació en 1990 y cuenta con los recursos de operación más importantes (un presupuesto de 44 millones de dólares y cerca de 100 funcionarios). Corresponde a la primera etapa de las privatizaciones, caracterizada por la improvisación y la búsqueda de credibilidad política por parte del gobierno. ${ }^{31}$ Sólo después de dos años, durante los cuales la comisión permaneció intervenida y $\sin$ estructura definitiva, se aprobó el reglamento de servicio telefónico básico, que busca limitar ciertas prácticas usuales de las empresas concesionarias (como, por ejemplo, la facturación de servicios no prestados). El ENRE y el ENARGAS han sufrido significativas demoras en su constitución, y fuertes presiones políticas han limitado de partida la autonomía declarada en los respectivos decretos constitutivos. Sus directorios y gerencias técnicas han sido completados más de un año después de la entrada en vigencia de las concesiones, y su capacidad efectiva de seguimiento era, a fines de 1993, aún dudosa. Ambos han debido intervenir en conflictos con repercusión social (por ejemplo, el corte masivo de la provisión eléctrica a los

\footnotetext{
${ }^{29}$ En realidad el sistema de regulación tiene varios componentes: la ley marco, la legislación específica para los servicios más importantes, las reglamentaciones de estas leyes, los contratos de concesión (prácticamente inaccesibles al escrutinio público) y, por último, los entes como encarnación del poder de policía del Estado. Por razones expositivas, este trabajo no analiza los contenidos de las leyes, sino solamente las capacidades actuales y limitaciones efectivas de los entes.

${ }^{30}$ En éste último caso, sólo a principios de 1994 se llamó a concurso para cubrir los puestos técnicos requeridos.

${ }^{31}$ Nótese que ninguno de los mercados correspondientes a las otras privatizaciones de esa primera etapa (concesión de rutas en peaje, venta de áreas petroleras y aeronavegación) tiene un marco regulatorio específico.
}

consumidores ilegales de zonas de bajos recursos), aunque algunos de sus dictámenes fueron desautorizados por el Poder Ejecutivo. Por otra parte, y como resultado de las auditorías de la calidad del servicio, los entes han impuesto multas -mínimas, pagadas bajo protesta- a las distribuidoras privadas, $y$ han ordenado la devolución al usuario de los montos derivados de sobrefacturaciones.

ii) Entes sin capacidad efectiva de regulación. Son aquellos que han sido instituidos legalmente pero que no cuentan con una estructura suficiente, o bien no disponen de autonomía porque dependen de las juridicciones administrativas encargadas -originalmente- de las privatizaciones.

En este grupo pueden mencionarse la Comisión Nacional de Correos y Telégrafos, empresa que todavía no ha sido privatizada; la Comisión Nacional de Transporte Ferroviario, que fiscalizará las concesiones del área; la Comisión Nacional de Regulación Ferroviaria, con competencia en los conflictos entre los usuarios, el Estado y los operadores; la Comisión de Concesiones Viales, que depende de la antigua Vialidad Nacional, y la Comisión Nacional del Transporte Automotor, dependiente de la Secretaría de Transporte.

iii) Areas sin organismos de regulación. En buena medida, los conflictos de interés han impedido la constitución de tales entes en la aeronavegación, el sector de refinación y comercialización del petróleo y la producción de gas, el transporte multimodal en el Gran Buenos Aires, los puertos y vías navegables, y otras áreas.

En líneas generales, tanto la estructura jurídica de los marcos regulatorios como las atribuciones formales de los respectivos entes parecen haber incorporado las recomendaciones derivadas de la experiencia internacional (invocaciones a tarifas justas y razonables, defensa de los derechos de los usuarios, de la libre competencia, de la eficiencia, etc.). Asimismo, las estructuras orgánicas de los entes han sido diseñadas por firmas consultoras de nivel internacional, las escalas salariales son adecuadas a la función, los puestos directivos y técnicos deben ser concursados públicamente y se han introducido cláusulas de incompatibilidad razonables.

Sin embargo, este tipo de prescripción carece de sentido práctico en tanto no quede sustentado y avalado por la letra chica de los contratos, y es en este aspecto donde subsisten serias dudas. La efectividad final de los 
entes de regulación depende en gran medida de su autonomía respecto de los concesionarios y de los funcionarios políticos, de su credibilidad ante la sociedad y de los dispositivos de seguimiento aplicados.

\section{Las enseñanzas de los primeros años de ges- tión 32}

Los entes de regulación en la Argentina han sido concebidos a partir de cada servicio o empresa privatizado; pero en forma independiente entre sí, y con posterioridad a las adjudicaciones de las concesiones y la consiguiente transferencia de los activos. Esta estrategia ha tenido diversas consecuencias: ${ }^{33}$

i) Inconsistencia de las políticas. Por ejemplo, los entes reguladores del gas y de la electricidad aparecen completamente disociados, complicando las tareas de programación de inversiones en el mediano y largo plazo, el diseño de políticas de sustitución energética y de uso racional de la energía, y otras. Por otro lado, una fuente de ingresos tan significativa como el petróleo carece de ente y de marco normativo específico. ${ }^{34}$ La misma clase de problemas puede emerger con el tiempo respecto de los diversos modos de transporte terrestre. ${ }^{35}$

ii) Poca coordinación de la información. Otra de las consecuencias negativas de la creación sucesiva y desarticulada de los entes de regulación consiste en que el Estado pierde la posibilidad de mantener una memoria centralizada y accesible. Este problema se ve potenciado por la variada naturaleza jurisdiccional de las funciones de regulación.

iii) Idoneidad profesional de la nueva tecnoestructura. Las nominaciones y el proceso de selección

\footnotetext{
32 Respecto de la experiencia internacional y latinoamericana puede consultarse OCDE (1993) y Rausch (1993).

33 Si bien estos problemas en cierto modo eran de esperar, teniendo en cuenta el contexto previo a las privatizaciones y la celeridad y profundidad que se imprimió al proceso, las posibilidades de corregir los desvíos se reducirán significativamente a partir de la prescripción, a mediados del próximo período de gobierno, de la posibilidad de iniciar acciones jurídicas que alteren el sistema actual. A partir de ese momento, se corre el riesgo cierto de que se consolide el estilo regulatorio de cooptación bifronte.

${ }^{34}$ De hecho, la administración central no ha logrado evitar alzas en el precio local de los combustibles. La única herramienta disponible para contrarrestar estas prácticas oligopólicas parece ser la precaria Ley de Defensa de la Competencia.

${ }^{35}$ Este problema se evitaría, por ejemplo, con la creación de un "superente" centralizado que impidiese la sobreespecialización del funcionario regulador y las mayores posibilidades de cooptación. En una economía en la cual los principales conglomerados empresariales dominan también el sector de servicios públicos privatizado, y en ausencia de una rigurosa ley antimonopolios, tal estructura resultaría imprescindible.
}

para llenar los cargos directivos de los entes no han surgido de concursos transparentes. En ocasiones, los responsables no son idóneos, sino más bien personas que responden políticamente a diversos grupos o agentes de poder.

iv) Status jurídico equívoco. En tanto que muchos de los pliegos de concesiones antedatan el cuerpo normativo detallado, cualquier cambio podría considerarse una alteración de las reglas del juego, restando poder de negociación a las autoridades gubernamentales. Esto puede dar pie a discusiones de carácter más bien técnico entre los entes y los concesionarios, y a frecuentes laudos a partir de consideraciones políticas en distintos niveles del Poder Ejecutivo. De ser así, la autarquía de los entes se diluirá, facilitando además el proceso de cooptación del regulador.

v) Escasa evidencia de que se defiendan los derechos del usuario. A manera de ejemplo cabe citar el intento de facturación del agua potable en bloque a los consorcios, con lo cual la empresa hubiera reducido de manera significativa sus gastos administrativos (al enviar una sola factura), y solucionado a la vez sus problemas de mora en el pago del servicio, puesto que la amenaza de corte alcanzaba a todos los usuarios del edificio, y el costo de cobro (o de financiación) de los deudores morosos quedaba a cargo del resto de los vecinos. Finalmente, intervino el poder político, posponiendo la implementación e incurriendo así, de hecho y de jure, en una violación al contrato de adjudicación donde efectivamente se autorizaba esta modalidad. Cabe aclarar que la cláusula provino del marco normativo de la ex Obras Sanitarias de la Nación, aunque no era aplicada.

En general, no parecen estar dadas las condiciones para una efectiva regulación y transparencia, puesto que los entes regulatorios no han precedido a las privatizaciones, no se ha instalado una nueva tecnoestructura independiente, el sistema no es transparente y comprensible para los usuarios, y las sanciones no se aplican en forma automática sino más bien "consensuadamente".

En síntesis, la racionalidad del programa de privatizaciones argentino ha quedado significativamente limitada al menos en dos sentidos. En primer lugar, porque no se cumplen supuestos críticos respecto del comportamiento microeconómico (la propensión a la inversión reproductiva de los agentes de acumulación privilegiados por el programa). Y en segundo lugar, porque aún no están en funcionamiento los mecanismos extramercado requeridos para aproximarse a soluciones óptimas bajo condiciones de prestación monopólica. 


\section{IV}

\section{Síntesis y conclusiones}

En lo que toca a las relaciones económicas, políticas y sociales, el programa de privatizaciones desarrollado en Argentina hasta fines de 1993 ha traido transformaciones de carácter estructural, y ha dejado numerosas enseñanzas respecto a los aciertos y desaciertos, a los costos y beneficios sociales y a las ventajas y desventajas de emprender un programa tan amplio y acelerado.

Más allá de las diferencias que pueden reconocerse entre las privatizaciones realizadas hasta 1991 y las concretadas en el bienio 1992-1993, la desestatización argentina presenta rasgos distintivos que la caracterizan y diferencian de otras experiencias internacionales contemporáneas.

$\mathrm{Al}$ respecto, es indudable que la celeridad de las realizaciones constituye el fenómeno más destacado. En poco más de tres años fue transferida al sector privado la casi totalidad de las empresas públicas productoras de bienes y prestadoras de servicios que, en su conjunto, generaban cerca del $8 \%$ del PIB total y alrededor del $20 \%$ de la inversión global en el país.

Esa celeridad y el acento en el cortoplacismo, permitió revertir en una primera instancia la crítica situación financiera del sector público. Asimismo, a partir de la capitalización de una importante cantidad de títulos de la deuda externa, mejoró tanto el posicionamiento argentino en los distintos ámbitos de renegociación de la deuda externa, como las relaciones institucionales con los grupos económicos locales.

Sin embargo, el privilegiar la celeridad ${ }^{36}$ conspiró contra la concreción de algunos objetivos expresados originalmente, y se contrapuso también a muchas de las recomendaciones emergentes de la incipiente normativa internacional en la materia. Así, hubo diversos objetivos que no pudieron alcanzarse; y a veces las realizaciones fueron inferiores a las que podrían haberse logrado con un programa de privatizaciones más orgánico y gradual.

${ }^{36}$ Al decir de Gerchunoff (1992), "la sed de reputación frente a la comunidad de negocios" impulsaba y aceleraba "su acción privatizadora". En realidad, como ha quedado demostrado en los últimos años, tal actitud gubernamental, y por consiguiente de la cúpula empresarial, ha desempeñado un papel protagónico en procura de necesarios apoyos político-institucionales y corporativos que permitieran viabilizar (cuando no sustentar) la política socioeconómica del actual gobierno.
A continuación se confrontan algunos de los objetivos con sus respectivos resultados reales:

i) Estímulo de la inversión en las empresas privatizadas, y sus efectos multiplicadores: las inversiones comprometidas contractualmente son mínimas y, dadas las insuficiencias y limitaciones del marco regulatorio, de difícil control; en los casos de inexistencia de compromisos efectivos la formación de capital exhibió niveles ínfimos, y por último, esas escasas inversiones se destinaron mayoritariamente a la adquisición de equipamiento importado.

ii) Resolución definitiva de los desequilibrios fiscales: en la generalidad de los casos el inicial efecto positivo se verá neutralizado en el mediano o largo plazo; la generalizada subvaluación de los activos transferidos redujo los ingresos fiscales; las exenciones y los beneficios impositivos concedidos a algunos consorcios adjudicatarios contraen la recaudación; la absorción de la casi totalidad de los pasivos de las empresas transferidas supone futuros egresos fiscales por concepto de amortización e intereses, etc.

iii) Reducción significativa del endeudamiento externo: más allá del corto plazo, el efecto de la capitalización de títulos de la deuda externa se ha visto más que compensado por el nuevo endeudamiento externo, tanto por parte de los consorcios adjudicatarios como por el propio sector público.

iv) Incorporación de tecnologías de gestión modernas, y mejoramiento de la eficiencia empresarial $y$ de la calidad de los servicios y de los bienes ofrecidos a la comunidad: por el momento, las mejoras relativas en el desempeño de buena parte de las empresas privatizadas resultan del profundo deterioro previo a su transferencia al sector privado.

v) Cambio global de las reglas del juego: se ha fortalecido el poder relativo de los mismos agentes económicos que crecieron al amparo, entre otras cosas, de la promoción industrial, de la estatización de la deuda externa privada, y de las compras de bienes y servicios del sector público, consolidando su poder de cabildeo y acrecentando su influencia sobre los precios relativos y la distribución de la riqueza. En tal sentido, más que contribuir a la generación de una nueva clase empresarial de características emprendedoras, las políticas públicas $-\mathrm{y}$ la de privatizaciones 
en particular - han contribuido a consolidar el poder de mercado de unos pocos conglomerados empresariales, localizados fundamentalmente en sectores que producen bienes y servicios no transables en el ámbito internacional .

Por otra parte, se han desatendido notoriamente algunos temas de importancia crucial para alcanzar los beneficios sociales que teóricamente podrían emanar de una selectiva y gradual política de privatización de empresas públicas. A título ilustrativo, basta con señalar la despreocupación por el saneamiento previo de las empresas que se pretende privatizar; la escasa atención brindada a la necesidad de regular determinadas áreas privatizadas; la transferencia y consolidación de reservas de mercados oligopólicos o monopólicos; el establecimiento de condiciones que aseguran riesgos empresariales bajos o nulos; la libertad en la fijación de las tarifas y de los cuadros tarifarios de diversos servicios públicos; la cesión a unos pocos agentes económicos del poder regulatorio sobre los mercados; las bruscas alteraciones en la estructura de precios relativos de la economía, en detrimento de los sectores productores de bienes transables en el mercado internacional y de los consumidores; el escaso interés por introducir licitaciones competitivas en las que pueda participar un número importante de oferentes y la fijación de "barreras al ingreso" sustentadas en la capacidad patrimonial de los potenciales oferentes, y la profundización del proceso de concentración y centralización del capital.

Asimismo, ha habido deficiencias normativas asociadas al tema de la regulación pública, particularmente en el caso de los 'monopolios naturales', y en aquellas áreas y sectores en que se ha consolidado una estructura fuertemente oligopolizada. Entre ellas cabe destacar: i) la formulación de marcos regulatorios y la constitución de los respectivos entes reguladores con posterioridad a la transferencia de las empresas públicas al sector privado; ii) las disposiciones tendientes a preservar el carácter monopólico u oligopólico de las empresas privatizadas. Aun cuando existen cláusulas que limitan el período

\footnotetext{
${ }^{37}$ Un caso ilustrativo en este sentido es el comportamiento de la firma YPF S.A., cuyas prácticas predatorias y anticompetitivas el gobierno no ha logrado restringir con los instrumentos disponibles.

${ }^{38}$ El ejemplo más notorio lo ofrece la adquisición por Acindar de una parte de las acciones de la ex Somisa, desvirtuando la condición impuesta en la privatización de que no podrían formar parte del mismo consorcio dos empresas siderúrgicas locales.
}

de ejercicio de estos derechos, el poder de negociación relativo de las partes al momento de la terminación de los contratos no favorecerá al Estado mientras persista la debilidad de los entes de regulación o su cooptación por los agentes económicos regulados; iii) la frecuente reformulación de normas establecidas con anterioridad a las licitaciones, que va en detrimento de la credibilidad pública del sistema regulatorio y puede llegar a vulnerar derechos adquiridos cuya renegociación perjudicaría casi con seguridad al Estado; iv) la escasa protección de los consumidores frente a prácticas oligopólicas de los consorcios adjudicatarios; ${ }^{37}$ v) la fijación de requisitos formalmente antimonopólicos que, sin embargo, en la práctica pueden ser fácilmente desvirtuados sin hacerse pasible a sanción alguna, ${ }^{38}$ y vi) la inexistencia de normas que tiendan a garantizar la independencia de los entes reguladores respecto de las empresas privadas adjudicatarias de las firmas o áreas privatizadas.

$\mathrm{La}$ experiencia argentina pone de relieve también algunos interrogantes relativos a la fuerte concentración de la propiedad de las empresas privatizadas en unos pocos grandes grupos económicos; ${ }^{39} \mathrm{en}$ ese marco, el creciente poder de negociación de los conglomerados debilita al propio Estado en su papel de articulador de las relaciones de la sociedad en su conjunto.

Por último, lo obrado en Argentina en materia de privatización y regulación de servicios públicos es casi antagónico con las mejores prácticas al respecto. ${ }^{40}$ En efecto, la mayor parte de las experiencias de privatización llevan a concluir que una vez tomada la decisión política de privatizar todas o algunas de las empresas públicas, es preciso aplicar un enfoque gradualista, con criterios de secuencia temporal que permitan armonizar y optimizar objetivos múltiples de corto y largo plazo, y atendiendo de partida a la reestructuración y el saneamiento de las empresas por privatizar, a fin de maximizar el valor de sus activos, y a la formulación previa de marcos regulatorios que garanticen los mayores beneficios sociales.

\footnotetext{
${ }^{39}$ Incluso, favorecidas por la "barrera al ingreso" que supone la fijación de montos patrimoniales mínimos para poder participar en las licitaciones, algunas de las grandes firmas integrantes de los consorcios adjudicatarios han transferido posteriormente sus tenencias accionarias, obteniendo ingentes beneficios financieros en un muy corto plazo.

40 Véase, entre otros, OCDE (1993), Devlin (1993) y Banco Mundial (1988).
} 


\section{Bibliografia}

Argentina, Ministerio de Economía y Obras y Servicios Públicos (1993): Argentina: un país para invertir y crecer, Buenos Aires.

Argentina, Poder Ejecutivo Nacional (1993): Argentina en crecimiento, 1993-1995, Nos I, II, III y IV, Buenos Aires, Ministerio de Economía y Obras y Servicios Públicos, mayo.

Azpiazu, D., A. Vispo y M. Fuchs (1993): La inversión en la industria argentina 1983-1988. El comportamiento heterogéneo de las principales empresas en una etapa de incertidumbre macroeconómica (1983-1988), Documento de trabajo, $\mathrm{N}^{\circ}$ 49, LC/BUE/L. 131, Buenos Aires, Oficina de la CEPAL en Buenos Aires.

Banco Mundial (1988): Techniques of Privatization of State-Owned Enterprises, World Bank Technical Paper, $N^{\circ} 93$, Washington, D.C.

Basualdo, E.M. (1994): El impacto económico y social de las privatizaciones, Realidad Económica, $\mathrm{N}^{\circ} 123$, Buenos Aires, Instituto Argentino para el Desarrollo Económico (IADE).

Canavese, A. y G. Rozenwurcell (1991): Privatizaciones, crecimiento y distribución del ingreso, A. Porto (ed.), Economía de las Empresas Públicas, Tesis-ITDT, Buenos Aires.

Coloma, G. (1992): Empresa pública y empresa privada: un análisis teórico de eficiencia comparada, P. Gerchunoff (ed.), Las privatizaciones en la Argentina. Primera etapa, Buenos Aires, Instituto Torcuato Di Tella.
(1993): Desempeño empresario y contexto económico: un análisis del periodo 1991-92, Documento de trabajo $\mathrm{N}^{\circ} 12$, Buenos Aires, U.I.A., Instituto para el Desarrollo Industrial, junio.

Devlin, R. (1993): Las privatizaciones y el bienestar social, Revista de la CEPAL, No 49, LC/G. 1757-P, Santiago de Chile, abril.

FIEL (Fundación de Investigaciones Económicas Latinoamericanas) (1992): Capital de infraestructura en la Argentina. Gestión pública, privatización y productividad, 1970-2000, Buenos Aires.

Gerchunoff, P. (ed.) (1992): Las privatizaciones en la Argentina. Primera Etapa, Buenos Aires, Instituto Torcuato Di Tella.

Nochteff, H. (1993): Constraints on the Transition to a Dynamic Economic System in Latin America. An Approach to some Socio-economic Conditionants for Development: The Argentine Case, Santiago de Chile, Facultad Latinoamericana de Ciencias Sociales (FLACSO), Programa Argentina, diciembre.

OCDE (Organización de Cooperación y Desarrollo Económicos) (1993): Regulatory Reform. Privatization and Competition Policy, París.

Piffano, H. (1991): Teoría positiva de la empresa pública, autonomía de gestión y control de la Gerencia, A. Porto (ed.), Economía de las empresas públicas, Tesis-ITDT, Buenos Aires.

Rausch, A. (1993): Monitoring and Regulatory Aspects of Privatization in Argentina and Latin America, Oxford, Programa de las Naciones Unidas para el Desarrollo (PNUD), julio. 